Open Access

\title{
Sustained weight loss in patients treated with mifepristone for Cushing's syndrome: a follow-up analysis of the SEISMIC study and long-term extension
}

Henry G. Fein ${ }^{1 *}$, T. Brooks Vaughan ${\| I^{2}}^{2}$, Harvey Kushner ${ }^{3}$, David $\mathrm{Cram}^{4}$ and Dat Nguyen ${ }^{4}$

\begin{abstract}
Background: Overweight and obesity are common among patients with Cushing's syndrome (CS) and may persist in some patients even after ostensibly curative surgery, contributing to cardiometabolic dysfunction and increased cardiovascular risk. Mifepristone, a selective glucocorticoid receptor antagonist, was effective in controlling hyperglycemia in a 24-week trial of adults $(N=50)$ with endogenous CS and associated type 2 diabetes mellitus/impaired glucose tolerance or hypertension who had failed or were not candidates for surgery (SEISMIC, Study of the Efficacy and Safety of Mifepristone in the Treatment of Endogenous Cushing's Syndrome). This analysis examines long-term weight change among patients who received mifepristone in SEISMIC and enrolled in a long-term safety extension (LTE) study.
\end{abstract}

Methods: Patients completing the 24-week SEISMIC study and subsequent 6-week off-drug safety evaluation were invited to enroll in the LTE study. Mifepristone doses at the end of SEISMIC were the LTE starting doses. Body weight measures were reviewed at baseline and week 24 of SEISMIC and at LTE month 6, 12, 18, 24, and final visit (last observation collected during the LTE study).

Results: Of the 30 patients enrolled in the LTE, evaluable weight data were available for 29 (20/29 female; mean age of $44.7 \pm 11.2$ years). These patients received mifepristone for a median of 29.2 months (range 8.4-41.9). Mean \pm SD weight from SEISMIC baseline to LTE final visit decreased by $10.3 \pm 16.3 \mathrm{~kg}$ (mean $105.4 \pm 34.3 \mathrm{~kg}$ to $95.1 \pm 32.9 \mathrm{~kg})$, a $9.3 \%$ decrease from baseline weight $(P=0.0008)$. Of the 29 LTE patients, $18(62.1 \%)$ lost $\geq 5 \%$ of body weight by the end of the initial 24-week treatment period; this $\geq 5 \%$ weight loss persisted in $83.3 \%$ $(15 / 18)$ at LTE final visit. Ten patients (34.5\%) lost $\geq 10 \%$ of initial body weight by week 24 of SEISMIC, which persisted in $80 \%$ at LTE final visit. No new safety signals were detected with long-term mifepristone use.

Conclusion: Clinically meaningful weight loss achieved during a 24-week study of mifepristone for CS persisted for two additional years in patients who remained on therapy. Long-term treatment with mifepristone appears to have a beneficial effect on weight in patients with endogenous CS.

Trial Registration: NCT00569582 (SEISMIC); NCT00936741 (Long-Term Extension).

Keywords: Cushing's syndrome, Korlym, Long-term, Mifepristone, Obesity, SEISMIC, Weight loss

\footnotetext{
* Correspondence: hfein@lifebridgehealth.org

'Johns Hopkins University School of Medicine and Sinai Hospital of

Baltimore, 2435 W. Belvedere Avenue, Baltimore, MD 21215, USA

Full list of author information is available at the end of the article
} 


\section{Background}

Endogenous Cushing's syndrome (CS), a complex metabolic disorder resulting from prolonged exposure to elevated cortisol, is associated with substantial morbidity and mortality, particularly in relation to cardiovascular events [1-4]. Obesity is a prominent feature of CS, with 70 to $80 \%$ of patients characterized as either overweight or obese [5-7]. Abdominal obesity contributes to insulin resistance, metabolic abnormalities, and cardiovascular risk in CS patients $[6,8,9]$. Although the mortality risk may decrease once remission of hypercortisolism is achieved, overall mortality and cardiovascular risk remain elevated in these patients when compared with control populations $[4,10]$. Surgical resection of an adrenocorticotropic hormone $(\mathrm{ACTH})$ - or cortisol-secreting tumor, which is the first-line treatment, often results in decreased body weight during early remission [11-13]. However, recent studies have shown that body weight can increase after initial improvement even if postoperative biochemical cure occurs $[7,8,14,15]$, which may be a contributing factor in the increased cardiovascular risk seen even where surgery was successful.

In patients with recurrent or persistent hypercortisolism, however-ie, in those for whom remission fails-mortality is increased compared with control populations (standardized mortality ratios 1.7-4.8) [3, 16, 17]. Given that longterm recurrence of hypercortisolism after initial surgical success following transsphenoidal pituitary surgery in patients with Cushing's disease (CD) has been reported in up to $66 \%$ of patients followed postoperatively for a mean duration of 14 years (range 1-37 years) $[11,18-22]$, recurrent disease is a major concern. Secondary treatment options for patients with recurrent or persistent endogenous CS, which may include pharmacologic therapy, are thus often utilized. Data on the long-term metabolic profiles of patients following pharmacologic treatments are needed.

Mifepristone (Korlym ${ }^{\circledR}$, Corcept Therapeutics, Menlo Park, CA), a glucocorticoid receptor antagonist, was associated with significant improvements in hyperglycemia in the 24-week SEISMIC (Study of the Efficacy and Safety of Mifepristone in the Treatment of Endogenous Cushing's Syndrome) trial; 15/25 (60 \%) had a $\geq 25 \%$ reduction in area under the curve for glucose and 21/40 (52.5\%) had either a $\geq 5 \mathrm{mmHg}$ reduction in diastolic blood pressure or reduction in antihypertensive medications [23]. A significant reduction in mean body weight in patients with CS was also noted during the study. Patients who completed the SEISMIC study could elect to enroll in a long-term safety extension (LTE) study. This report presents follow-up data examining the persistent effects of mifepristone on weight parameters in patients from the SEISMIC study who subsequently entered the LTE study.

\section{Methods}

Details of the study design and patient population of SEISMIC have been previously published [23]. SEISMIC was a 24-week, open-label, multicenter study of mifepristone administered as a once-daily oral dose to adults with confirmed endogenous CS who had type 2 diabetes mellitus, impaired glucose tolerance, or a diagnosis of hypertension [23] and had failed or were not candidates for surgery. Mifepristone was started at a dose of $300 \mathrm{mg} /$ day, with titration to a maximum of $1200 \mathrm{mg} /$ day based on investigator clinical discretion. At the end of SEISMIC, patients underwent a 6-week off-drug safety evaluation period. Of the 34 patients who completed SEISMIC, 30 elected to enroll in the LTE study. The starting dose in the LTE was the same as the final dose in SEISMIC, with further dose titration at the discretion of the treating clinical investigators. The study designs were approved by the Western Institutional Review Board (Puyallup, WA) and an institutional review board at each study center [23]. Written informed consent was obtained from all patients for both studies. Patients were free to discontinue from the studies at any time.

This analysis reviews weight assessments taken at baseline and week 24 of SEISMIC as well as at months $6,12,18,24$, and final visit (each patient's last observation) of the LTE study. Waist circumference and body composition were assessed in SEISMIC, but not the LTE. Safety was assessed throughout the SEISMIC and extension studies via adverse events (AEs), vital signs, physical exams, and clinical laboratory tests.

\section{Statistical analysis}

All numerically continuous data are presented as mean \pm SD unless otherwise specified. The percentage change in body weight from baseline was evaluated across time points using a mixed-model repeated-measures analysis of variance. No imputations for missing data were performed. Weight loss was evaluated descriptively using a categorical loss of at least $5 \%$ of the patient's body weight. A Kaplan-Meier plot was constructed based on the time to achieve weight loss of $\geq 5 \%$ in SEISMIC and throughout the LTE. A separate plot was constructed to show time to achieve weight loss of $\geq 10 \%$. Time was right censored for patients who did not complete the LTE. Weight loss persistence was defined as a loss of at least $5 \%$ of body weight at week 24 of SEISMIC that was maintained to the indicated study visits in the LTE trial. An additional analysis evaluated weight loss of $\geq 10 \%$ at week 24 of SEISMIC that was maintained at this threshold to the indicated study visits in the LTE trial. All P-values $\leq 0.05$ were considered statistically significant and no Bonferroni corrections for simultaneous multiple inferences were performed. All analyses were performed using SAS version 9.2 software (SAS Institute, Cary, NC). 


\section{Results}

Patients

Of the 30 CS patients enrolled in the LTE (Fig. 1), evaluable body weight data were available for 29 patients (20 women and 9 men; mean age, $44.7 \pm 11.2$ years) (Table 1 ), who were treated with mifepristone at an average daily dose of $758 \pm 290 \mathrm{mg}$. Twenty-six patients had CD and three patients had ectopic ACTH. Baseline biochemical status is reported in Table 2. Patients were treated in the LTE for a median of 29.2 months (range 8.4-41.9 months), and 25 patients received therapy for at least 2 years. At baseline in the SEISMIC study, six patients (20.7\%) were overweight (BMI 25-29) and 21 (72.4 \%) were obese (BMI $\geq 30$ ); nine had a BMI $\geq 40$. The mean waist circumference was $122.4 \pm 23.9 \mathrm{~cm}$.

\section{Weight loss and change in body composition during SEISMIC and LTE}

Among the 29 patients included in this analysis, mean waist circumference decreased by $9.3 \mathrm{~cm}$ in women and $8.3 \mathrm{~cm}$ in men from baseline to week 24 of SEISMIC. Mean percent total body fat declined by $3.7 \%$ in women and $0.3 \%$ in men, and percent trunk fat declined by $2.5 \%$ in women and $1.2 \%$ in men by week 24 of SEISMIC. On the other hand, mean total lean body mass increased by $3.9 \%$ in women and $1.3 \%$ in men by week 24 of SEISMIC. Percentage decreases in body weight from baseline were significant at weeks 10-24 of SEISMIC (all $P<0.0001$ ) and at each assessment in the LTE (all $P<0.0001$ ) (Fig. 2). A $7.5 \%$ decrease in weight was observed from baseline to week $24(P<0.0001)$. At the 24-week visit during SEISMIC, $62.1 \%$ (18/29) of patients had lost $\geq 5 \%$ of baseline body weight. An additional analysis found $34.5 \%$ (10/29) of patients lost $\geq 10 \%$ of baseline body weight at the end of SEISMIC.

By the end of the LTE, $86 \%(25 / 29)$ achieved $\geq 5 \%$ weight loss, while $72 \%(21 / 29)$ achieved $\geq 10 \%$ weight loss. The crude rate for the $10 \%$ weight loss was lower than the life-table estimate observed in the Kaplan-Meier plot (Fig. 3, $80 \%$ for $\geq 10 \%$ weight loss). A $9.3 \%$ decrease

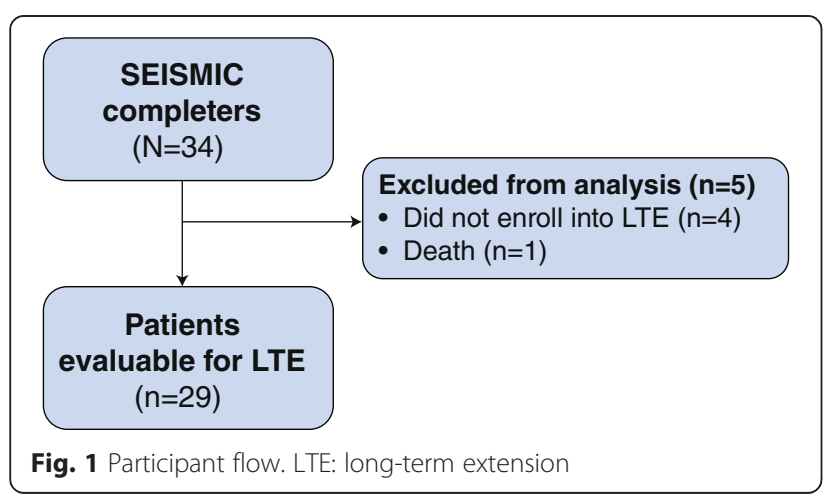

Table 1 Demographic and baseline characteristics of patients with evaluable body weight enrolled in the LTE study

\begin{tabular}{ll}
\hline Characteristic & LTE population $(n=29)$ \\
\hline Sex, $n$ (\%) & $9(31)$ \\
Male & $20(69)$ \\
Female & \\
Race, $n(\%)$ & $24(83)$ \\
White & $5(17)$ \\
Black or African American & \\
Age, y & $44.7(11.2)$ \\
Mean (SD) & 26,71 \\
Min, max & \\
Weight, kg & $105.4(34.3)$ \\
Mean (SD) & $61.3,198.7$ \\
Min, max & \\
BMl, kg/m ${ }^{2}$ & $37.7(11.7)$ \\
Mean (SD) & $24.1,66.4$ \\
Min, max & \\
BMl category, $n$ (\%) & $2(6.9)$ \\
$<25$ & $6(20.7)$ \\
$25-29$ & $21(72.4)$ \\
$\geq 30$ & $9(31)$ \\
$\geq 40$ & \\
\hline
\end{tabular}

$B M I$ body mass index; LTE long-term extension

in weight was observed from baseline to final visit in the LTE $(P=0.0008)$ (Table 3$)$.

\section{Persistence of weight loss from SEISMIC across LTE}

Of the 18 patients who lost $\geq 5 \%$ of body weight by the end of the 24-week treatment period, $83.3 \%(n=15)$ maintained $\geq 5 \%$ weight loss at final visit in the LTE study (Table 4). Twelve of the 18 patients lost additional weight in the LTE (7 lost $\geq 5 \%, 5$ lost $<5 \%$ ). The six patients with weight gain during the LTE still had an average net loss of $3.23 \%(1.9 \pm 4.4 \mathrm{~kg})$ when compared to baseline in SEISMIC. Of the ten patients who lost $\geq 10 \%$ of body weight during SEISMIC, 80 \% maintained that degree of weight loss by the LTE final visit.

\section{Safety}

All patients $(n=29)$ reported at least one AE during the LTE; the most common AEs reported were nausea (52\%), decreased blood potassium (48 \%), fatigue (45 \%), headache (38\%), and endometrial thickening (35\%). Three patients discontinued from the study because of AEs $(n=1$ each: adrenal insufficiency, endometrial thickening, endometrial disorder). During the LTE, the term "adrenal insufficiency" was used to describe the events experienced by five patients. Three of these events were associated 
Table 2 Baseline biochemistry for patients with evaluable weight data enrolled in the LTE study

\begin{tabular}{llll}
\hline Variable, mean (SD) & Cushing's disease $(n=26)$ & Ectopic ACTH $(n=3)$ & Overall $(n=29)$ \\
\hline ACTH, $\mathrm{pg} / \mathrm{mL}$ & $54.5(33.6)$ & $180.0(158.0)$ & $67.5(65.6)$ \\
$24 \mathrm{~h}$ UFC, $\mu \mathrm{g} / 24 \mathrm{~h}$ & $144.9(153.2)$ & $3158.4(3625.3)$ & $456.6(1353.5)$ \\
Serum cortisol, $\mu \mathrm{g} / \mathrm{dL}$ & $21.1(5.8)$ & $44.5(16.9)$ & $23.5(10.2)$ \\
Late-night salivary cortisol, $\mu \mathrm{g} / \mathrm{dL}$ & $0.31(0.32)$ & $2.5(2.4)$ & $0.56(1.0)$ \\
\hline
\end{tabular}

$A C T H$ adrenocorticotropic hormone; UFC urinary free cortisol; LTE long-term extension

with co-existing infections. The symptoms of "adrenal insufficiency" were effectively managed with interruption of mifepristone and administration of dexamethasone in four patients and interruption of mifepristone without glucocorticoid supplementation in one patient. Severe hypokalemia (serum potassium $\leq 2.5 \mathrm{mEq} / \mathrm{L}$ ) was reported in four patients, which resolved with treatment that included potassium supplements and mineralocorticoid antagonists. No patients discontinued from the LTE because of hypokalemia.

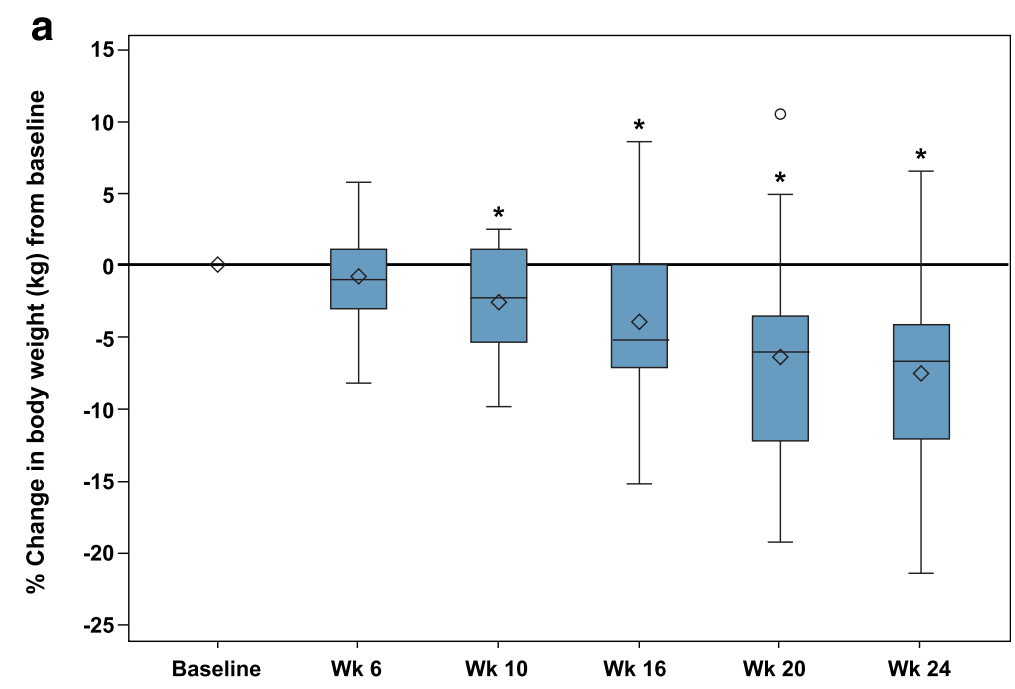

b

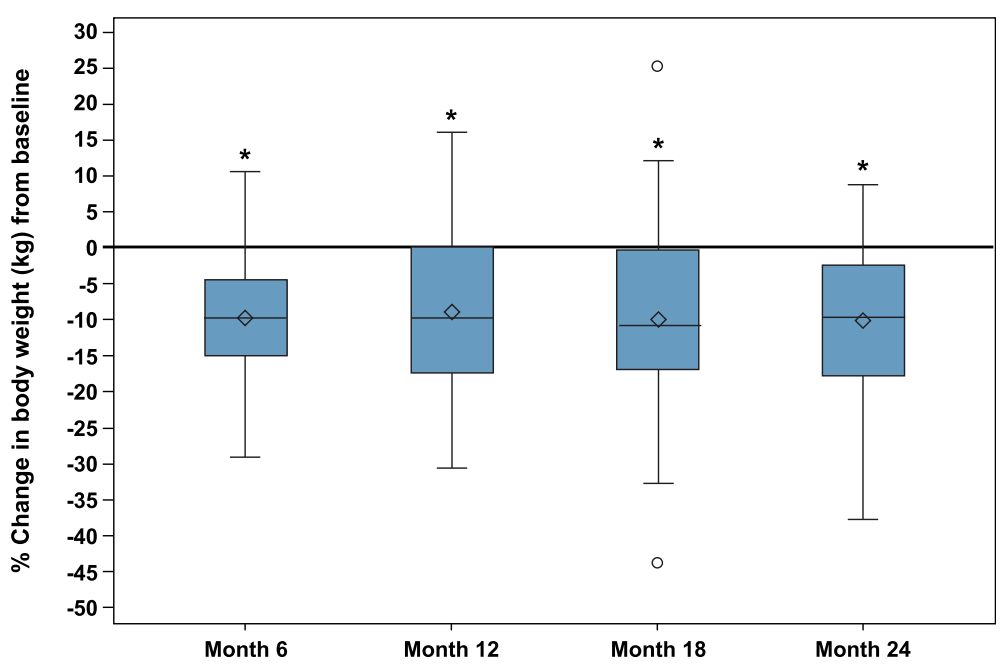

Fig. 2 Mean percent change in body weight from baseline in SEISMIC by visit in a SEISMIC and by month in $\mathbf{b}$ LTE. *The changes from baseline were statistically significant from weeks $10-24$ in the 24-week treatment period and at each time point in the long-term extension $(P<0.0001)$. Diamonds = means; horizontal lines within boxes = medians; ends of boxes $=25$ th/75th percentiles; "whiskers" = range of the min to the max but not longer than 1.5 times the interquartile range (IQR); circles = values beyond the 1.5 IQR. LTE: long-term extension 


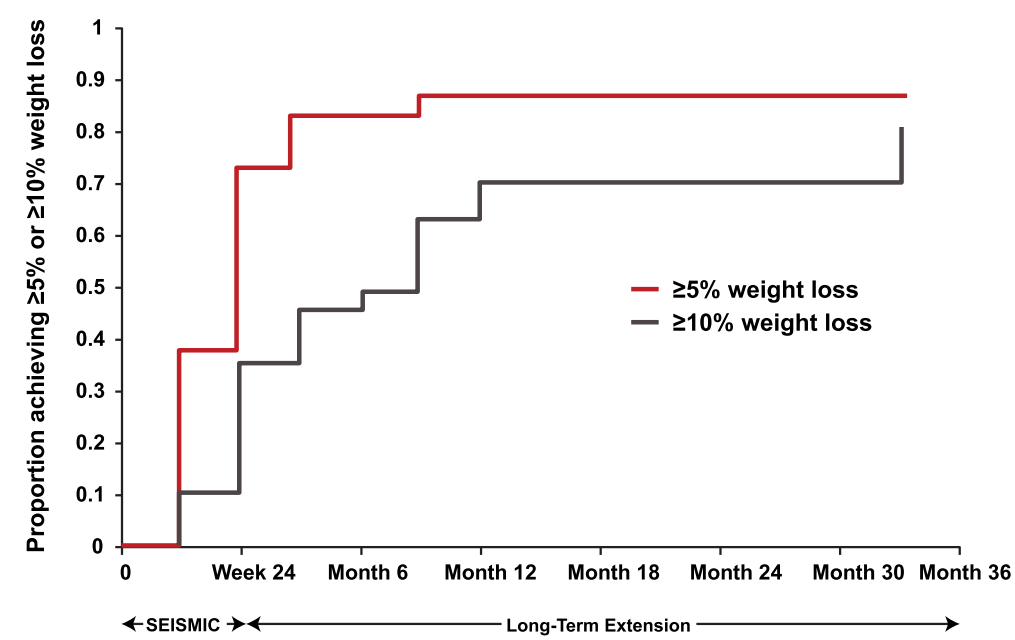

Fig. 3 Kaplan-Meier plot for proportion of patients achieving $\geq 5$ and $\geq 10 \%$ weight loss in SEISMIC and the LTE. LTE: Iong-term extension

\section{Discussion}

In CS, hypercortisolism can promote cardiometabolic abnormalities similar to that of metabolic syndrome, including increased abdominal fat, hypertension, diabetes mellitus, and hyperlipidemia $[6,8,24,25]$, which contribute to the increased cardiovascular risk and mortality in these patients [2-4]. Terzolo et al. recently examined cardiovascular risk among patients with CS, followed at least 12 months postoperatively [10]. Patients with persistent disease following surgery $(n=24)$ continued to have elevated rates of hypertension (79\%), diabetes (54\%), central obesity $(77 \%)$, and elevated triglycerides (54\%) after 12 months, with little change compared to rates at diagnosis. Among patients in remission $(n=51)$, the rate of hypertension decreased by $41 \%$, central obesity decreased by $37 \%$, diabetes decreased by $17 \%$, and elevated triglycerides decreased by $16 \%$ compared with diagnosis. However, despite the improvements following resolution of hypercortisolism, the rates of central obesity and elevated triglycerides remained significantly higher than the control population (45 vs $13 \% ; P=0.0002$ and 25 vs $5 \% ; P=0.005$, respectively). Therefore, increased emphasis is needed to address CS-related comorbidities, including cardiovascular risk, before and after remission of hypercortisolism is achieved, as noted in recent CS guidelines [17]. However, long-term data will be needed to determine if improvement in cardiovascular risk factors in patients with CS will lead to a further reduction in mortality.

While cardiovascular risk was not formally assessed in the 6-week SEISMIC trial, treatment with mifepristone was shown to improve glucose parameters in patients with CS that were refractory to other therapies and who had associated type 2 diabetes mellitus, impaired glucose tolerance, or hypertension $[23,26]$. Walia et al. further demonstrated that large improvements in glucose tolerance and insulin sensitivity occurred during the first 6 weeks of mifepristone treatment [26] and continued to improve as beneficial changes in weight and waist circumference were attained at week 24 . Our current study

Table 3 Persistence of weight loss in SEISMIC and the LTE

\begin{tabular}{|c|c|c|c|c|c|}
\hline \multirow[b]{2}{*}{ Variable } & \multicolumn{2}{|l|}{ SEISMIC } & \multicolumn{3}{|l|}{ LTE } \\
\hline & Baseline $(n=29)$ & Week $24(n=29)$ & Month $6(n=27)$ & Month $18(n=25)$ & Final visit $(n=29)$ \\
\hline \multicolumn{6}{|l|}{ Weight, kg } \\
\hline Mean \pm SD & $105.4 \pm 34.3$ & $97.2 \pm 30.8$ & $95.2 \pm 32.2$ & $96.6 \pm 34.7$ & $95.1 \pm 32.9$ \\
\hline Change weight & - & $-8.2 \pm 9.3$ & $-10.5 \pm 12.3$ & $-11.4 \pm 18.7$ & $-10.3 \pm 16.3$ \\
\hline$\%$ Change in weight & - & $-7.5 \pm 7.1$ & $-9.7 \pm 9.7$ & $-10.0 \pm 14.4$ & $-9.3 \pm 13.4$ \\
\hline \multicolumn{6}{|l|}{$\mathrm{BMl}, \mathrm{kg} / \mathrm{m}^{2}$} \\
\hline Mean \pm SD & $37.7 \pm 11.7$ & $34.7 \pm 10.0$ & $34.3 \pm 9.7$ & $34.0 \pm 9.7$ & $33.7 \pm 9.9$ \\
\hline \multicolumn{6}{|l|}{ BMl category, n (\%) } \\
\hline$\geq 30$ & $21(72.4)$ & $17(58.6)$ & $16(59.3)$ & $16(64.0)$ & $18(62.1)$ \\
\hline$\geq 40$ & $9(31.0)$ & $7(24.1)$ & $6(22.2)$ & $4(16.0)$ & $6(20.7)$ \\
\hline
\end{tabular}

Final visit is defined as the last post-entry observation collected during the LTE study $B M I$ body mass index; LTE long-term extension 
Table 4 Categorical weight loss in SEISMIC and persistence during the LTE study

\begin{tabular}{lll}
\hline Categorical weight loss in SEISMIC & Time point in LTE study & Weight loss persistence ${ }^{\mathrm{a}}, n(\%)$ \\
\hline $\mathbf{2} \%$ weight loss $(n=18)^{\mathrm{b}}$ & Month 6 & $14(82.4)$ \\
& Final visit & $15(83.3)$ \\
$\geq 10 \%$ weight loss $(n=10)^{\mathrm{b}}$ & Month 6 & $8(80)$ \\
& Final visit & \\
\hline
\end{tabular}

${ }^{a}$ Persistence is defined as maintenance of the weight loss threshold in SEISMIC to LTE assessment time points. ${ }^{\mathrm{b}}$ One subject was excluded from this analysis because the only post-baseline weight was assessed on the day of death, which occurred in the hospital in relation to a serious adverse event deemed not related to study drug by the investigator. 'Final visit is defined as the last post-entry observation collected during the LTE study LTE long-term extension

demonstrated that weight loss of $\geq 5 \%$ is maintained and can persist for up to 3.5 years of mifepristone treatment. A weight loss of 5-10\% has been shown to reduce cardiovascular risk factors in other at-risk populations $[27,28]$. For example, a randomized, multicenter trial of obese and overweight patients with type 2 diabetes found that a weight loss of 5 to $<10 \%$ after 1 year of intensive lifestyle intervention was associated with a statistically significant improvement in cardiovascular risk factors including reductions in glycated hemoglobin $\left(\mathrm{A}_{1 \mathrm{c}}\right)$ and blood pressure [27].

Long-term therapy with mifepristone in patients with CS was associated with an AE profile comparable to that reported in the 24-week SEISMIC study [23]. There were five reported cases of "adrenal insufficiency" during the LTE, and all cases resolved with temporary drug interruption with or without supplemental glucocorticoid administration. Yuen et al. [29] recently described how symptoms of "excessive glucocorticoid receptor antagonism" associated with mifepristone can resemble some symptoms of adrenal insufficiency (eg, nausea, fatigue, vomiting, and low appetite). However, serious symptoms of adrenal crisis, such as hypotension or hyperkalemia, are unlikely to occur due to the rise in cortisol levels and subsequent activation of the mineralocorticoid receptors during mifepristone therapy. If clinical signs or symptoms of excessive glucocorticoid receptor antagonism are suspected, therapy with mifepristone should be discontinued temporarily, and in some cases, administration of supplemental glucocorticoids may be useful. Treatment can be resumed at a lower dose once signs and symptoms of excessive glucocorticoid receptor antagonism are resolved.

This follow-up analysis of clinical trial data contributes useful information on the long-term use of mifepristone and weight loss in patients with CS. Other cardiometabolic parameters, such as glycemic control, waist circumference, and blood pressure, were not routinely assessed during the LTE, nor did this study control for patient-specific factors such as diet, physical activity, or other lifestyle modifications. Likewise, the influence of disease etiology on weight outcomes was not examined because of the limited number of patients that enrolled in the LTE with diagnoses other than CD. Additional studies in patients with CS to assess long term metabolic and cardiovascular benefits associated with sustained weight loss from cortisol blockade with mifepristone are warranted. It remains to be determined whether sustained improvement in cardiovascular risk factors will translate to reduced mortality in patients with CS.

\section{Conclusion}

A follow-up analysis of clinical trial data found clinically meaningful weight loss ( $\geq 5 \%$ of body weight) achieved during short-term mifepristone use was sustained in approximately $80 \%$ of patients with CS who were treated with mifepristone for up to 3.5 years. No new safety signals were detected with long-term mifepristone use.

\section{Abbreviations}

ACTH: Adrenocorticotropic hormone; BMI: Body mass index; CD: Cushing's disease; CS: Cushing's syndrome; LTE: Long-term extension; SEISMIC: Study of the Efficacy and Safety of Mifepristone in the Treatment of Endogenous Cushing's Syndrome.

\section{Competing interests}

HGF - Research funding (site investigator for this study): Corcept

Therapeutics; Speaker's bureau: Corcept Therapeutics.

TBV - Research funding (site investigator for this study): Corcept

Therapeutics.

HK - Consultant: Corcept Therapeutics.

DC - Employee: Corcept Therapeutics.

DN - Employee: Corcept Therapeutics.

\section{Authors' contributions}

Concept and design (DC, DN); acquisition of data (HGF, TBV); analysis and interpretation of data (HGF, TBV, HK, DC, DN); statistical analysis (HK); drafting of the manuscript (HGF, DN); critical revision of the manuscript for intellectual content (HGF, TBV, HK, DC, DN); administrative, technical, or logistical support (DN); decision to publish (HGF, TBV, HK, DC, DN). All authors read and approved the final manuscript.

\section{Acknowledgment}

The authors thank Coleman Gross, MD, formerly of Corcept Therapeutics, for his contributions to study concept, data analysis, and first draft; and Sarah Mizne, PharmD, of MedVal Scientific Information Services, LLC, for providing medical writing and editorial assistance. This study was sponsored by Corcept Therapeutics, Menlo Park, CA. Corcept participated in the study conception and design; collection, analysis, and interpretation of the data; and review of the manuscript. Funding to support the preparation of this manuscript was provided to MedVal Scientific Information Services, LLC, by Corcept Therapeutics, who also paid the article processing fee. This manuscript was prepared according to the International Society for Medical Publication Professionals' "Good Publication Practice for Communicating Company-Sponsored Medical Research: the GPP3 Guidelines" and the International Committee of Medical Journal Editors' "Uniform Requirements for Manuscripts Submitted to Biomedical Journals." 


\section{Previous presentation}

Data from this study were presented at ICE/ENDO 2014, June 23, 2014, Chicago, IL.

\section{Author details}

${ }^{1}$ Johns Hopkins University School of Medicine and Sinai Hospital of Baltimore, 2435 W. Belvedere Avenue, Baltimore, MD 21215, USA. ²Division of Endocrinology, Diabetes \& Metabolism, University of Alabama at Birmingham School of Medicine, BDB 706, 1720 2nd Avenue South, Birmingham, AL 35294, USA. 3BioMedical Computer Research Institute, 9743 Redd Rambler Place, Philadelphia, PA 19115, USA. ${ }^{4}$ Corcept Therapeutics, 149 Commonwealth Drive, Menlo Park, CA 94025, USA.

Received: 15 April 2015 Accepted: 16 October 2015

Published online: 27 October 2015

\section{References}

1. Nieman LK, Biller BMK, Findling JW, Newell-Price J, Savage MO, Stewart PM, et al. The diagnosis of Cushing's syndrome: an Endocrine Society Clinical Practice Guideline. J Clin Endocrinol Metab. 2008;93(5):1526-40.

2. Dekkers OM, Horvath-Puho E, Jorgensen JO, Cannegieter SC, Ehrenstein V, Vandenbroucke JP, et al. Multisystem morbidity and mortality in Cushing's syndrome: a cohort study. J Clin Endocrinol Metab. 2013;98(6):2277-84.

3. Clayton RN, Raskauskiene D, Reulen RC, Jones PW. Mortality and morbidity in Cushing's disease over 50 years in Stoke-on-Trent, UK: audit and metaanalysis of literature. J Clin Endocrinol Metab. 2011;96(3):632-42.

4. Ntali G, Asimakopoulou A, Siamatras T, Komninos J, Vassiliadi D, Tzanela M, et al. Mortality in Cushing's syndrome: systematic analysis of a large series with prolonged follow-up. Eur J Endocrinol. 2013;169(5):715-23.

5. Pivonello R, Faggiano A, Lombardi G, Colao A. The metabolic syndrome and cardiovascular risk in Cushing's syndrome. Endocrinol Metab Clin North Am. 2005;34(2):327-39.

6. Faggiano A, Pivonello R, Spiezia S, De Martino MC, Filippella M, Di SC, et al. Cardiovascular risk factors and common carotid artery caliber and stiffness in patients with Cushing's disease during active disease and 1 year after disease remission. J Clin Endocrinol Metab. 2003;88(6):2527-33.

7. Giordano R, Picu A, Marinazzo E, D'Angelo V, Berardelli R, Karamouzis I, et al. Metabolic and cardiovascular outcomes in patients with Cushing's syndrome of different aetiologies during active disease and 1 year after remission. Clin Endocrinol (Oxf). 2011;75(3):354-60.

8. Colao A, Pivonello R, Spiezia S, Faggiano A, Ferone D, Filippella M, et al. Persistence of increased cardiovascular risk in patients with Cushing's disease after five years of successful cure. J Clin Endocrinol Metab. 1999;84(8):2664-72.

9. Pivonello R, De LM, Vitale P, Cozzolino A, Simeoli C, De Martino MC, et al. Pathophysiology of diabetes mellitus in Cushing's syndrome. Neuroendocrinology. 2010;92 Suppl 1:77-81.

10. Terzolo M, Allasino B, Pia A, Peraga G, Daffara F, Laino F, et al. Surgical remission of Cushing's syndrome reduces cardiovascular risk. Eur J Endocrinol. 2014;171(1):127-36.

11. Biller BMK, Grossman AB, Stewart PM, Melmed S, Bertagna X, Bertherat J, et al. Treatment of adrenocorticotropin-dependent Cushing's syndrome: a consensus statement. J Clin Endocrinol Metab. 2008;93(7):2454-62.

12. Tritos NA, Biller BM. Medical management of Cushing's disease. J Neurooncol. 2014;117(3):407-14.

13. Geer EB, Shen W, Strohmayer E, Post KD, Freda PU. Body composition and cardiovascular risk markers after remission of Cushing's disease: a prospective study using whole-body MRI. J Clin Endocrinol Metab. 2012;97(5):1702-11.

14. Espinosa-de-Los-Monteros AL, Sosa E, Martinez N, Mercado M. Persistence of Cushing's disease symptoms and comorbidities after surgical cure: a long-term, integral evaluation. Endocr Pract. 2013;19(2):252-8.

15. Barahona MJ, Sucunza N, Resmini E, Fernandez-Real JM, Ricart W, MorenoNavarrete JM, et al. Persistent body fat mass and inflammatory marker increases after long-term cure of Cushing's syndrome. J Clin Endocrinol Metab. 2009;94(9):3365-71.

16. Lindholm J, Juul S, Jorgensen JO, Astrup J, Bjerre P, Feldt-Rasmussen U, et al. Incidence and late prognosis of Cushing's syndrome: a populationbased study. J Clin Endocrinol Metab. 2001;86(1):117-23.

17. Nieman LK, Biller BM, Findling JW, Murad MH, Newell-Price J, Savage MO, et al. Treatment of Cushing's syndrome: an Endocrine Society clinical practice guideline. J Clin Endocrinol Metab. 2015;100(8):2807-31.
18. Atkinson AB, Kennedy A, Wiggam MI, McCance DR, Sheridan B. Long-term remission rates after pituitary surgery for Cushing's disease: the need for long-term surveillance. Clin Endocrinol. 2005;63(5):549-59.

19. Dimopoulou C, Schopohl J, Rachinger W, Buchfelder M, Honegger J, Reincke $\mathrm{M}$, et al. Long-term remission and recurrence rates after first and second transsphenoidal surgery for Cushing's disease: care reality in the Munich Metropolitan Region. Eur J Endocrinol. 2014;170(2):283-92.

20. Hassan-Smith ZK, Sherlock M, Reulen RC, Arlt W, Ayuk J, Toogood AA, et al. Outcome of Cushing's disease following transsphenoidal surgery in a single center over 20 years. J Clin Endocrinol Metab. 2012;97(4):1194-201.

21. Patil CG, Prevedello DM, Lad SP, Vance ML, Thorner MO, Katznelson L, et al. Late recurrences of Cushing's disease after initial successful transsphenoidal surgery. J Clin Endocrinol Metab. 2008;93(2):358-62.

22. Aranda G, Ensenat J, Mora M, Puig-Domingo M, de Osaba MJ M, Casals G, et al. Long-term remission and recurrence rate in a cohort of Cushing's disease: the need for long-term follow-up. Pituitary. 2015;18(1):142-9.

23. Fleseriu M, Biller BM, Findling JW, Molitch ME, Schteingart DE, Gross C. Mifepristone, a glucocorticoid receptor antagonist, produces clinical and metabolic benefits in patients with Cushing's syndrome. J Clin Endocrinol Metab. 2012;97(6):2039-49.

24. Valassi E, Santos A, Yaneva M, Toth M, Strasburger CJ, Chanson P, et al. The European Registry on Cushing's syndrome: 2-year experience. Baseline demographic and clinical characteristics. Eur J Endocrinol. 2011;165(3):383-92.

25. Valassi E, Crespo I, Santos A, Webb SM. Clinical consequences of Cushing's syndrome. Pituitary. 2012;15(3):319-29.

26. Wallia A, Colleran K, Purnell JQ, Gross C, Molitch ME. Improvement in insulin sensitivity during mifepristone treatment of Cushing syndrome: early and late effects. Diabetes Care. 2013;36(9):e147-8.

27. Wing RR, Lang W, Wadden TA, Safford M, Knowler WC, Bertoni AG, et al. Benefits of modest weight loss in improving cardiovascular risk factors in overweight and obese individuals with type 2 diabetes. Diabetes Care. 2011;34(7):1481-6.

28. Wadden TA, Hollander P, Klein S, Niswender K, Woo V, Hale PM, et al. Weight maintenance and additional weight loss with liraglutide after lowcalorie-diet-induced weight loss: the SCALE Maintenance randomized study. Int J Obes. 2013;37(11):1443-51.

29. Yuen KC, Williams G, Kushner H, Nguyen D. Association between mifepristone dose, efficacy, and tolerability in patients with Cushing's syndrome. Endocr Pract. 2015;21(10):1087-92.

\section{Submit your next manuscript to BioMed Central and take full advantage of:}

- Convenient online submission

- Thorough peer review

- No space constraints or color figure charges

- Immediate publication on acceptance

- Inclusion in PubMed, CAS, Scopus and Google Scholar

- Research which is freely available for redistribution 